\title{
Chronic Ankle Contracture Reduced: A case series
}

\author{
by Sarah A. Curran, PhD, BSc(Hons), FCPodMed, FHEA ${ }^{1 \rrbracket}$, F. Buck Willis, PhD $^{2 凹}$
}

Background: Contracture is molecular shortening of connective tissue that frequently occurs from arthrofibrosis following malleolar fractures, causing plantarflexion contracture. The purpose of this case series was to examine reduction of chronic contracture of ankle fracture patients with treatment of dynamic splinting which delivers prolonged durations of low-load stretching at end range (s) of motion.

Method: Eighteen patients (mean age 46, range 29 - 65 years, 9 females, 9 males) with a prior history of medial malleolar fracture, surgical fixation and contracture of more than one year took part. Dynamic splinting was prescribed for wear each night, achieving 6 to 8 hours of passive end-range stretching. The tension of the Dynasplint ${ }^{\circledR}$ was changed twice a month to optimize the stretch at end range of motion.

Results: The mean duration was 16 weeks (range 12-22 weeks) and the patients mean wear was 784 hours (range 660 - 960) in end-range therapy from dynamic splinting. Maximal dorsiflexion was measured at baseline (enrolment) and at four months. The mean maximal change in dorsiflexion was $23.4^{\circ}(S D=14.1)$.

Discussion and Conclusion: Contracture reduction is thought to require comparable amounts of time equaling the duration of contracture development. Low force, prolonged, passive stretching is considered to have the most beneficial effect in contracture reduction due to its ability to facilitate permanent changes in connective tissue elongation. The $60 \%$ change in maximal dorsiflexion noted in this study can be directly related to the duration of treatment as home therapy. A larger controlled trial should be conducted to measure empirical efficacy of dynamic splinting for contracture reduction following malleolar fractures.

The Foot and Ankle Online Journal 4 (7): 2 reproduction in any medium, provided the original work is properly cited. @The Foot and Ankle Online Journal (www.faoj.org), 2011 All rights reserved.

A nkle fractures are commonly treated with surgical intervention and/or immobilization. frequently following both of these treatment options. ${ }^{1-7}$ Nightingale, et al., ${ }^{1}$ tracked the reduction of contracture in patients following fracture

Address correspondence to: Sarah A. Curran, $\mathrm{PhD}, \mathrm{BSc}(\mathrm{Hons})$, FCPodMed, FHEA. Email: scurran@uwic.ac.uk

\footnotetext{
1 Senior Lecturer, Wales Centre for Podiatric Studies, University of Wales Institute, Cardiff, Western Avenue, Cardiff, CF5 2YB, UK. Phone +44 (0) 29 20417221.

${ }^{2}$ Clinical Research Director, Landmark Medical, Dynasplint Systems, PO Box 1735 San Marcos TX, USA. Phone: +1 78667 (512) 2971833.
}

immobilization and noted that even with manual therapy, recovery was incomplete after three months for both maximal active range of motion (AROM) and passive range of motion (PROM). In an earlier study, Moseley, et al., ${ }^{2}$ examined efficacy of passive stretching on plantarflexion contracture following immobilization for fractures. Patients were grouped into "short duration" passive stretching for 6 minutes per day and a second group for 30 minutes per day, called "long-duration" passive stretching. They found 
no significant difference in the 4 week or 3 month testing durations. The "longer duration" in this study however, was only $7 \%$ of the "Prolonged Durations" of passive stretching shown effective in numerous studies that employed low torque and prolonged stretching. ${ }^{8-12}$

The premise behind the protocol of dynamic splinting is that greater durations at end-range (of motion) will elongate the connective tissue with hypothetical realignment of elastin polypeptide bonds on collagen trihedral structures. ${ }^{8,10,15}$ A study in contracture reduction compared high versus. (vs.) low torque and short vs. prolonged durations of stretching on surgically induced contracture in rats. ${ }^{8}$ The findings only showed a significant difference between the combined protocols for the low torque with prolonged duration of stretching. This findings is also supported in recent studies on low torque, prolonged end-range stretching have shown efficacy in contracture reduction in the jaw, shoulder, elbow, carpal tunnel, knee, ankle, foot, and toe..$^{9-20}$

One example of this protocol is in the treatment of plantar fasciopathy with prolonged stretching in dorsiflexion. Plantar fasciopathy, also known a plantar fasciitis is a common problem worldwide and can be attributed to contracture of the plantar fascia. In a randomized, multicentre trial, Sheriden, et al., ${ }^{21}$ examined the efficacy of dynamic splinting in 60 patients (76 feet) with plantar fasciopathy. After a physical examination and testing for differential diagnosis, patients were administered the Plantar Fasciitis Pain Scale which is a 100-point survey that measures frequency and intensity of pain in activities of daily living. Experimental patients wore the dynamic splinting devices each night to produce prolonged, low-load, dynamic tension. These patients wore the dynamic splint device for 6 to 8 continual hours (while sleeping) for 12 weeks. On completion, it was noted that the experimental patients had a mean 33 point improvement (reduction) in pain scale scores, compared to only 3 point change for the control patients $(\mathrm{p}<0.0001)$.
This case series sought to examine the reduction of chronic contracture of ankle fracture patients using dynamic splinting which delivers prolonged durations of low-load stretching at end-range(s) of motion.

\section{Method}

The case series consisted of eighteen patients who had suffered a malleolar fracture and received surgical internal fixation of more than one year. Informed consent was taken from each patient, but formal Institutional Review Board review was not accomplished because there was not a control arm or anything deviating from Standard of Care in reducing contracture. All patients presented with a plantarflexion contracture which had been unresolved for more than one year. Maximal active range of motion in dorsiflexion was the dependent variable in this study and was measured upon enrolment and at four months. This measurement was obtained using a standard goniometer while the patient was seated and the knee flexed to $90^{\circ}$.

\section{Intervention}

Patients were prescribed Dynasplint ${ }^{\circledR}$ for nightly wear, achieving six to eight hours of stretching each night and the tension was increased every two weeks. The tension was increased twice a month to keep stretching at the optimal end range of motion. After an Ankle dorsiflexion Dynasplint ${ }^{\circledR}$ was prescribed, a Dynasplint ${ }^{\circledR}$ specialist custom fit the modality to each patient's foot. Modifications for length and girth were made to each patient as required. (Dynasplint ${ }^{\circledR}$ Systems, Inc. Severna Park, MD, USA). (Fig. 1)

Patients were then instructed how to remove and apply the unit properly, as well as adjust the tension for planned increases in tension every two weeks The incremental changes in tension was based on patient tolerance. Tracking was accomplished to ensure compliance with a monthly diary. Each patient wrote the duration and tension level for each night's wear and was asked to note any discomfort (i.e. yes or no). 


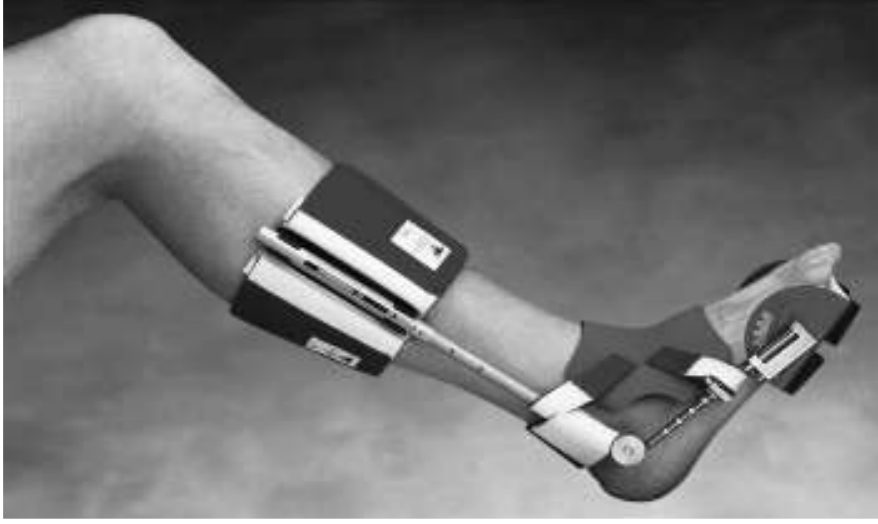

Figure 1 Dynasplint ${ }^{\circledR}$ for ankle joint dorsiflexion. (with permission from Dynasplint ${ }^{\circledR}$ Systems, Severna Park, MD, USA)

\section{Results}

This case series consisted of 9 females and 9 males with a mean age of 46.4 years (standard deviation [SD] 11.8, range $29-65$ years). The mean duration of wear was 16 weeks (SD 2.9, range 12 - 22 weeks) and the patients averaged a mean 784 hours (SD 94.5, range $960-660$ hours) in end-range therapy from dynamic splinting. Maximal ankle dorsiflexion measured upon enrolment (baseline) and four months showed a mean change of $23.4^{\circ}$. The range of difference was $5-54^{\circ}$, with only three of the patients showing a $5^{\circ}$ increase in maximum dorsiflexion from baseline to follow-up. The remainder of the patients $(n=15)$ had an improvement over beyond $10^{\circ}$. None of the patients reported any discomfort during the period of wear.

\section{Discussion}

Tension of gastrocnemius is seen to be a causative factor that contributes to contracture. ${ }^{22}$ Whilst DiGiovanni, et al., noted a significant difference in maximal dorsiflexion for ankle equinus patients versus control in full knee extension. ${ }^{22}$ No significant difference was observed in maximal dorsiflexion when measured in the seated position $(p=0.09)$. Stretching protocols for contracture have been documented as effective in reduction and it is suggested that the total duration of time at end-range of motion is the integral variable for the greatest success. ${ }^{8,911,12}$ Mosely, et al., tested passive stretching, but their total durations of stretching in the four week study were 2.8 hours (short duration group stretching $6 \mathrm{~min} /$ day) and 15 hours (long duration stretching 30 minutes per day). ${ }^{2} \quad$ This supports the evidence that "prolonged passive stretching" (6-8 continuous hours) is required for contracture reduction..$^{8-14,16-21}$

The patients in this case series achieved a mean 784 hours of end-range stretching in four months. Therefore, 196 hours of end-range stretching in the first month accounts for the different findings. This prolonged duration of passive, end-range stretching supports the findings by Usuba, et al., when comparing durations of stretching. ${ }^{8}$ Moreover, evidence from previous studies on dynamic splinting show empirical efficacy in prolonged duration of stretching at end-range stretching. ${ }^{9-20}$ More specifically, these benefits compare favorably with Lai, et al., who observed neurological patients with chronic contracture ${ }^{14}$, as well as the observations made in this case series.

Range of maximum ankle joint dorsiflexion was a key outcome measure used in this case study, and whilst a $60 \%$ increase in range of motion is acknowledged, the authors are aware of the error of measurement associated with clinical goniometric measurements. For example, the standard error of measurement (SEM) for ankle joint dorsiflexion has been reported as $2.1^{\circ}{ }^{23}$ Although the lowest change of $5^{\circ}$ was noted in three patients, this value can still be considered as clinically significant. The role of the SEM however becomes less crucial with the remaining fifteen patients as motion improved by $>10^{\circ}$ which comfortably supersedes the SEM and further strengthens the actual improvement in range of motion. Whilst no causal inferences can be established about the relationship between the intervention (i.e. Dyansplint ${ }^{\circledR}$ ) and outcome, it has provided the foundation for exploring this form of modality further using studies which have more methodological rigor (i.e. randomized controlled trials). 


\section{Conclusion}

The benefits of this case series serves as a means of initially reporting on the intervention of dynamic splinting for chronic ankle contracture. The next step is to therefore examine the efficacy of dynamic splinting with a superior methodological rigor. This will therefore examine the true efficacy of dynamic splinting against another testing mechanism such as a balance platform.

\section{Competing interests}

SAC is the Chief Editor and FBW is the Associate Editor-in-Chief of the Foot and Ankle Online Journal and were removed from the peer review process and editorial decision for this manuscript.

\section{References}

1. Nightingale EJ, Moseley AM, Herbert RD. Passive dorsiflexion flexibility after cast immobilization for ankle fracture. Clin Orthop Relat Res 2007 456: 65-69.

2. Moseley AM, Herbert RD, Nightingale EJ, Taylor DA, Evans TM, Robertson GJ, Gupta SK, Penn J. Passive stretching does not enhance outcomes in patients with plantarflexion contracture after cast immobilization for ankle fracture: a randomized controlled trial. Arch Phys Med Rehabil 2005 86:1118-126.

3. Koval KJ, Zhou W, Sparks MJ, Cantu RV, Hecht P, Lurie J.et al. Complications after ankle fracture in elderly patients. Foot Ankle Int 2007 28: 1249-1255.

4. Barrett MO, Wade AM, Della Rocca GJ, Crist BD, Anglen JO. The safety of forefoot metatarsal pins in external fixation of the lower extremity. JBJS 2008 90A: 560-564.

5. Lui TH, Chan KB, Kong CC, Ngai WK. Ankle stiffness after Bosworth fracture dislocation of the ankle. Arch Orthop Trauma Surg 2008 128: 49-53.

6. Heybeli N, Ozcan M, Yalniz E. Ankle stiffness and osteoarthritis in fracture-dislocation: an avoidable complication or natural history. Arch Orthop Trauma Surg 2008 128: 639640.

7. De Vries G, Roy K, Chester V. Using three-dimensional gait data for foot/ankle orthopaedic surgery. Open Orthop J 2009 3: 89-95.

8. Usuba M, Akai M, Shirasaki Y, Miyakawa S. Experimental joint contracture correction with low torque--long duration repeated stretching. Clin Orthop Relat Res 2007 456: 70-78.
9. Stubblefield MD, Manfield L, Riedel ER. A preliminary report on the efficacy of a dynamic jaw opening device (dynasplint trismus system) as part of the multimodal treatment of trismus in patients with head and neck cancer. Arch Phys Med Rehabil 2010 91: 1278-1282.

10. Gaspar PD, Willis FB. Adhesive capsulitis and dynamic splinting: a controlled, cohort study. BMC Musculoskelet Dis 2009 10:111.

11. Berner SH, Willis FB. Dynamic splinting in wrist extension following distal radius fractures. J Orthop Surg Res 2010 5: 53.

12. Berner SH, Willis FB, Shanmugan R. Pain from carpal tunnel syndrome reduced with dynamic splinting: a retrospective study of 156 patients. J Clin Med Res 2009 1:22-25.

13. Berner SH, Willis FB, Martinez J. Treatment of carpal tunnel syndrome with dynasplint: a randomized, controlled trial. J Medicine 2008 1: 1-5.

14. Lai J, Jones M, Willis B. Effect of dynamic splinting on excessive plantar flexion tone/contracture: A controlled, crossover study. Proceedings of the $16^{\text {th }}$ European Congress of Physical and Rehabilitation Medicine. Minerva Medica pubs, Italy, August 2008, 106-109.

15. Anderson DS, Willis FB. Contracture reduction following total knee arthroplasty, a cohort series of 107 patients. Clin Rehab (In-Press).

16. Sheridan L, Lopez AL, Perez A, John MM, Willis FB, Shanmugam R. Plantar fasciopathy treated with dynamic splinting: a randomized, controlled, trial. JAPMA 2010 100:161165.

17. Lopez AA, Kalish SR, John MM, Willis FB. Reduction of ankle equinus contracture secondary to diabetes mellitus with Dynamic Splinting. FAOJ 2010 3: 3.

18. John MM, Willis FB, Portillo A. Runner's hallux rigidus reduction and gait analysis. JAPMA 2009 99:367-370.

19. Kalish SA, Willis FB. Hallux limitus and dynamic splinting: a retrospective series. FAOJ 2009 2:4.

20. John MM, Kalish SR, Perns SV, Willis, FB. Dynamic splinting for hallux limitus: a randomized, controlled trial. JAPMA (In-Press).

21. Willis FB, Lopez AL, Perez A, Sheridan L, Kalish SA. Pain scale for plantar fasciopathy. FAOJ 2009 2: 5.

22. DiGiovanni CW, Kuo R, Tejwani N, Price R, Hansen ST Jr, Cziernecki J, Sangeorzan BJ. Isolated gastrocnemius tightness. JBJS 2002 84A: 962-970.

23. Van Gheluwe B, Kirby KA, Roosen P, Phillips RD.

Reliability and accuracy of biomechanical measurements of the lower extremities. JAPMA 2002 92: 317-326. 